\title{
Silver nanoparticle engineering via oligovaline organogels
}

\author{
Alexandre Mantion, ${ }^{a}$ A. Geraldine Guex, ${ }^{a}$ Annette Foelske, ${ }^{b}$ Laurent Mirolo, ${ }^{c}$ Katharina M. Fromm, ${ }^{c}$ \\ Monika Painsi ${ }^{d}$ and Andreas Taubert ${ }^{* a e f}$
}

L-Valine-based oligopeptides with the chemical structure $\mathrm{Z}-(\mathrm{L}-\mathrm{Val})_{3}-\mathrm{OMe}$ and $\mathrm{Z}-(\mathrm{L}-\mathrm{Val})_{2}-\mathrm{L}-\mathrm{Cys}$

(S-Bzl)-OMe form stable organogels in butanol. Both peptides are efficient gelators, but $\mathrm{Z}-(\mathrm{L}-\mathrm{Val})_{2}-$ L-Cys $(\mathrm{S}-\mathrm{Bzl})-\mathrm{OMe}$ crystallizes more readily than $\mathrm{Z}-(\mathrm{L}-\mathrm{Val})_{3}-\mathrm{OMe}$. The two peptides can form mixed fibers, which also gel butanol. The resulting organogels are very similar to oligovaline organogels reported earlier (Mantion and Taubert, Macromol. Biosci., 2007, 7, 208) as they also form highly ordered peptide fibers with a predominant $\beta$-sheet structure and diameters of $c a .100 \mathrm{~nm}$. The fibers can be mineralized with silver nanoparticles using DMF as a reducing agent. The fraction of the sulfurcontaining peptide $\mathrm{Z}-(\mathrm{L}-\mathrm{Val})_{2}-\mathrm{L}-\mathrm{Cys}(\mathrm{S}-\mathrm{Bzl})-\mathrm{OMe}$ controls the shape and size of the resulting nanoparticles. At high Z-(L-Val $)_{2}-\mathrm{L}-\mathrm{Cys}(\mathrm{S}-\mathrm{Bzl})-\mathrm{OMe}$ content, small spherical particles are distributed all over the fiber. Lower contents of $\mathrm{Z}-(\mathrm{L}-\mathrm{Val})_{2}-\mathrm{L}-\mathrm{Cys}(\mathrm{S}-\mathrm{Bzl})-\mathrm{OMe}$ lead to a size increase of the particles and to more complex shapes like plate-like and raspberry-like silver particles. The interactions between peptide and silver ions or silver particles takes place via a complexation of the silver ions to the sulfur atom of the thioether moiety, and are shown to be the key interaction in controlling particle formation.

\section{Introduction}

Metal colloids and their assemblies have arguably become one of the most popular research fields since the original discovery of colloidal gold by Michael Faraday and their subsequent rediscovery in the late $20^{\text {th }}$ century. ${ }^{1-3}$ Since the development of the so-called Brust-Shiffrin method, ${ }^{4,5}$ extensive work has been done on the synthesis and physical properties of colloidal metal particles. This includes studies on the role of particle composition (pure particles $v$. doping or alloying), surface modification with organic or inorganic structures like additional shells or (bio)molecules, particle shape and size etc. on the optical and electronic properties of such nanoparticles and nanoparticle arrays. ${ }^{6,7}$ Interestingly however, there are only a few reports on the formation of metallic particles in organogels, in particular in peptide organogels. ${ }^{8-10}$ This is intriguing because peptides and peptide self-assembly are nowadays quite well understood. Peptide scaffolds should therefore be prime candidates for the fabrication of ordered nanoparticle arrays with more or less rationally designed structures and properties.

There are only a few examples of silver nanoparticle synthesis and supramolecular organization using small peptides and

${ }^{a}$ Department of Chemistry, Klingelbergstr. 80, University of Basel, Basel, CH-4056, Switzerland

${ }^{b}$ Electrochemistry Laboratory, Paul Scherrer Institute, Villingen, CH5232, Switzerland

${ }^{c}$ Department of Chemistry, University of Fribourg, Chemin du Musée 9, Fribourg, CH-1700, Switzerland

${ }^{d}$ Institute of Geological Sciences, University of Bern, Baltzerstrasse 1-3, Bern, CH-3012, Switzerland

${ }^{e}$ Institute of Chemistry, University of Potsdam, Karl-Liebknecht-Str. 2425, Golm, Building 26, D-14476, Germany. E-mail: ataubert@unipotsdam.de; Tel: +49 (0)3319775773

${ }^{f}$ Max-Planck-Institute of Colloids and Interfaces, Golm, D-14476, Germany proteins as templates or scaffolds. Tryptophan- and tyrosinecontaining peptides have been used as gelators and growth modifiers for silver colloids in aqueous solution and organic solvent-water mixtures. ${ }^{11-13}$ Djalali and Chen, and Slocik and Wright have used histidine-rich residues for templating gold nanocrystals and other noble metal nanoclusters. ${ }^{14,15}$ These studies all show that peptides can act as in situ reducing agents and/or as nucleation centers for the formation of silver with various shapes.

Proteins have also been reported to control the spatial organization of silver nanoparticles in one and two dimensions. This is done by exploiting the spatial organization of cysteine residues on the protein surface and the corresponding thiol-metal nanoparticle interactions. Alternatively, weak interactions like peptide non-specific adsorption, metal pre-concentration, or amine stabilization on the fiber also play a role. ${ }^{14-17}$

Up to now, there have been no reports on thiol or thioether incorporation into rather stiff (stiff compared to thiols in solution) supramolecular assemblies like peptide fibers and the effect of such templates on metal nanoparticle formation, but we have recently reported the formation of oligovaline organogels where

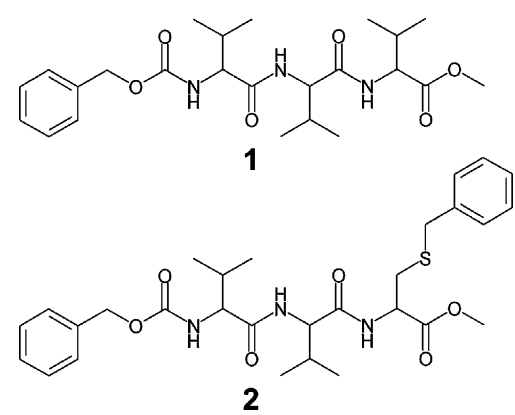

Scheme 1 Oligopeptides used in the current study. All amino acids are L-amino acids. 
the peptide fibers act as templates for various $\mathrm{TiO}_{2}$ morphologies. ${ }^{18}$ Here we report that by simply replacing the C-terminal valine with a benzyl-protected cysteine, Scheme 1, the same oligovaline family can be used for the fabrication of supramolecular scaffolds for silver nanoparticle mineralization. The ratio of the pure oligovaline $1 v s$. the sulfur-containing peptide $\mathbf{2}$ in the gel allows for a simple control over the silver-mineralization reaction.

\section{Results}

\section{Gels before mineralization}

The structural similarity between gels of either pure $\mathbf{1}$ or pure $\mathbf{2}$ and mixed gels containing $\mathbf{1}$ and $\mathbf{2}$ was studied by $\mathrm{X}$-ray diffraction and IR spectroscopy. Fig. 1 shows IR spectra of various gels. IR spectroscopy reveals that the gels form through $\beta$-sheet formation of the individual peptide building blocks. The IR spectra of all gels are virtually indistinguishable, indicating that they all have the same structural organization. However, much like in our previous study ${ }^{18}$ we cannot unambiguously distinguish between parallel or anti-parallel $\beta$-sheets due to the presence of the carbamate and methyl ester carbonyl bands, which overlap with the diagnostic antiparallel/parallel $\beta$-sheet vibrations at $1700 \mathrm{~cm}^{-1}$.

Fig. 2 shows X-ray patterns of the same gels. Overall, XRD indicates a moderately ordered structure without any particular features. XRD patterns of gels of pure 1 exhibit two reflections at $18.8(d$-spacing of $4.7 \AA)$ and $22.2(d$-spacing of $3.9 \AA)$ degrees $2 \theta$, which we earlier assigned to a fiber structure similar to poly (valine). ${ }^{18}$ Interestingly, the current XRD data show that the addition of peptide $\mathbf{2}$ to peptide $\mathbf{1}$ improves the order within the fibers. The increasing number of (narrow) reflections observed with increasing fraction of $\mathbf{2}$ in the gels suggests that the additional thioether functionality and the additional aromatic ring further stabilize the peptide 2 when compared to the pure tri-valine peptide $\mathbf{1}$. It also suggests that peptide 2 leads to a somewhat more crystalline order in the fibers.

Overall, XRD shows that all samples have a similar structural organization, which is consistent with IR spectroscopy. Closer inspection reveals minute shifts (below 0.8 degrees $2 \theta$ ) in the XRD patterns of the different samples. This indicates that there are slight differences between samples containing different fractions of $\mathbf{1}$ and $\mathbf{2}$, which however does not affect the overall

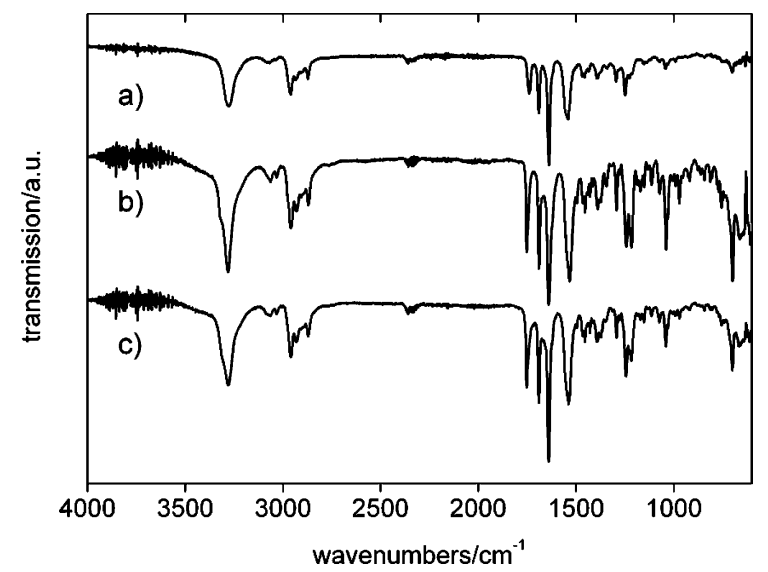

Fig. 1 IR spectra of gels with (a) pure 2, (b) $50 \%$ of $\mathbf{1}$ and $50 \%$ of $\mathbf{2}$, and (c) pure 1 .

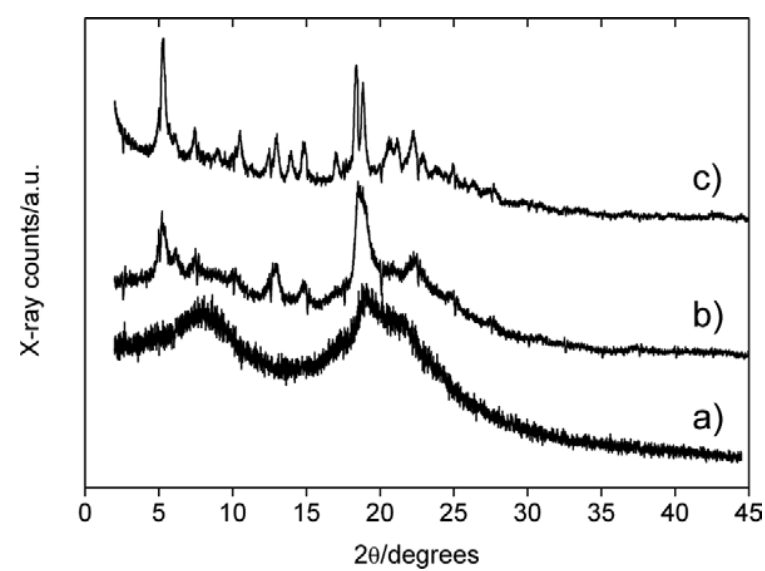

Fig. 2 XRD patterns of gels with (a) pure 1, (b) $50 \%$ of $\mathbf{1}$ and $50 \%$ of $\mathbf{2}$, and (c) pure 2 .

organization of the peptide assemblies. These differences are attributed to minor size differences between $\mathbf{1}$ and $\mathbf{2}$, similar to a study by Sunde et al. ${ }^{19}$ The fact that the transition between fibers of pure $\mathbf{1}$ and pure $\mathbf{2}$ does not show abrupt structural changes implies that the two peptides are structurally similar enough to not disturb their respective supramolecular order upon co-assembly.

Finally, XRD indicates that all peptides fibers adopt an amyloid quaternary structure upon gelation, regardless of their composition (pure peptides or mixtures of $\mathbf{1}$ and $\mathbf{2}$ ). The helical pitch of the structure is $115 \AA$, as determined from the reflections at 18.3(5), 18.8(3), 30.9(0), 39.6(9) degrees $2 \theta$. This matches earlier data by Sunde et al. ${ }^{19}$ on proteins self-assembling into amyloid fibrils. The pitch corresponds to 25 peptides in the helical repeating unit as is classically accepted for amyloid fibers. ${ }^{19,20}$
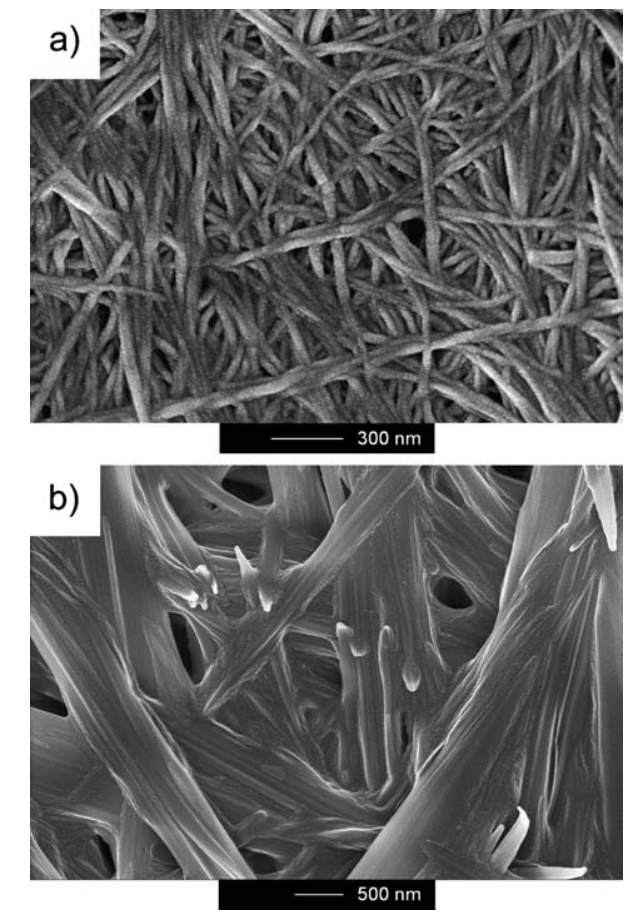

Fig. 3 SEM images of gels before mineralization. (a) Pure 1, and (b) pure 2. 
Fig. 3 shows representative SEM images of some gels. SEM shows that in all cases the peptides self-assemble into long fibers with a diameter of $c a .60 \mathrm{~nm}$ (pure 1), $25 \mathrm{~nm}$ (mixtures of 1 and 2), and $500 \mathrm{~nm}$ (pure 2). The latter value may not be from the individual fibers, as those large fibers seem to be composed of thinner fibers as well. These could, however, not be resolved.

The fibers of pure $\mathbf{2}$ often appear somewhat "crystalline" in that they exhibit edges or flat areas that could be poorly developed crystal faces. This is further supported by the fact that gels formed from pure 2 show additional reflections in XRD, Fig. 2. We therefore conclude that 2 forms peptide fibers and gels, but SEM and XRD also provide circumstantial evidence that $\mathbf{2}$ crystallizes more readily than $\mathbf{1}$. This higher tendency towards crystallization is assigned to the presence of an additional aromatic ring in the thioether moiety of $\mathbf{2}$. The resulting $\pi-\pi$ stacking interaction at least partially favors crystallization of $\mathbf{2}$. The combination of $\mathbf{1}$ and $\mathbf{2}$ in one fiber, however, completely inhibits the formation of larger crystalline units. This finding is further evidenced by the fact that the gels with (large fractions) of $\mathbf{2}$ are opaque, whereas the gels with $\mathbf{1}$ and mixtures of $\mathbf{1}$ and $\mathbf{2}$ are transparent to very slightly opaque.

\section{Mineralized gels}

Fig. 4 shows that the IR spectra remain unaffected by the mineralization process. This indicates that there is no change in the supramolecular structure of the self-organized fibers upon silver deposition. Specifically, IR spectroscopy shows that the vibration at $1634 \mathrm{~cm}^{-1}$ indicative of the $\beta$-sheet is conserved. ${ }^{18}$ Furthermore, IR shows that the chemical integrity of the peptides is maintained and the peptides are not damaged during mineralization because the spectra of the precursor gels and the mineralized gels are identical. Even the thioether moiety is unaffected by silver mineralization. This is evidenced by the fact that no $-\mathrm{SH}$ band (indicative of thioether cleavage) is observed at $c a$. $2550 \mathrm{~cm}^{-1}$. Moreover, there are no sulfone or sulfoxide bands at $1100-1300$ and at $1050 \mathrm{~cm}^{-1}$ indicative of sulfur oxidation.

The only significant change between the non-mineralized and the mineralized gels are several peak shifts. The carbonyl band of the methyl ester at $1738 \mathrm{~cm}^{-1}$ shifts by $24 \mathrm{~cm}^{-1}$ compared to the pure organogel. This shows that the methyl ester is not

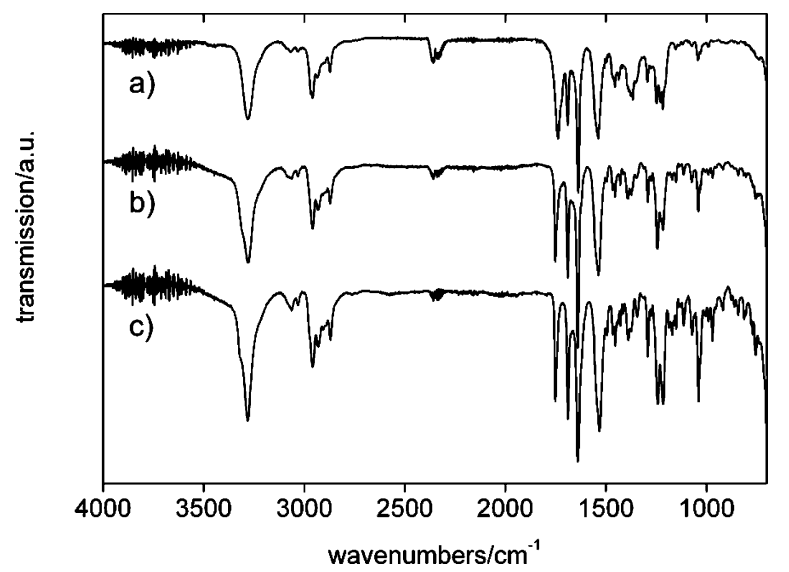

Fig. 4 IR of the gels after mineralization. (a) Pure gel of 1, (b) mixture of $50 \% \mathbf{1}$ and $\mathbf{2}$, and (c) pure $\mathbf{2}$. hydrolyzed, because the band persists, but that its local environment changes. Contrary to the work of Si and Mandal, ${ }^{11}$ our approach to silver deposition does not involve strong bases or alkaline conditions. As a result, the methyl ester is not cleaved and remains intact. Furthermore, the amide II band at 1529 $\mathrm{cm}^{-1}$ shifts by $3 \mathrm{~cm}^{-1}$, but remains strong and intact, showing that the integrity of the peptide backbone is unaffected by the silver deposition and there is no significant structural change either. $^{11}$

Overall, IR spectroscopy shows that there are some interactions of the peptides with the silver crystals, most prominently via the carbonyl group of the methyl ester. The quite large shift of over $20 \mathrm{~cm}^{-1}$ indicates that the interaction is quite strong. However, the fact that the band does not disappear upon mineralization also shows that the methyl ester is not cleaved during mineralization. IR spectroscopy therefore clearly confirms that the silver deposition using DMF in oligovaline organogels is a soft method leaving the peptide scaffold intact.

Fig. 5 shows SEM images of the mineralized gels. The images clearly show that the gel structure is conserved, that is, that the fibers are intact even after mineralization. In all cases, the peptide fibers are comparable to their non-mineralized analogs, but they are covered with particles of different shapes and sizes.

The fibers containing only $\mathbf{2}$ or a large fraction of $\mathbf{2}$ are densely covered with small particles with a diameter of $c a .9 \mathrm{~nm}$. Some larger particles are also present. As the fraction of $\mathbf{2}$ in the fibers decreases, the particles grow larger. Also, the decreasing fraction of 2 leads to the formation of more diverse particle shapes. Particles with triangular and related shapes are the predominant species at $50 \%$ of $\mathbf{2}$. At even lower contents of $25 \%$ of $\mathbf{2}$, most silver particles are above $100 \mathrm{~nm}$ in size and partly have well-defined triangular and related shapes. Mineralization of gels of pure 1 leads to samples with large particles of various shapes where the silver particles appear to be no longer tightly associated with the peptide fibers. In all cases some fraction of the $c a .9 \mathrm{~nm}$ particles is also visible.

These data show that the gels composed only of peptide $\mathbf{1}$ are only weak growth modifiers or inhibitors for silver, whereas increasing fractions of $\mathbf{2}$ make them more and more efficient
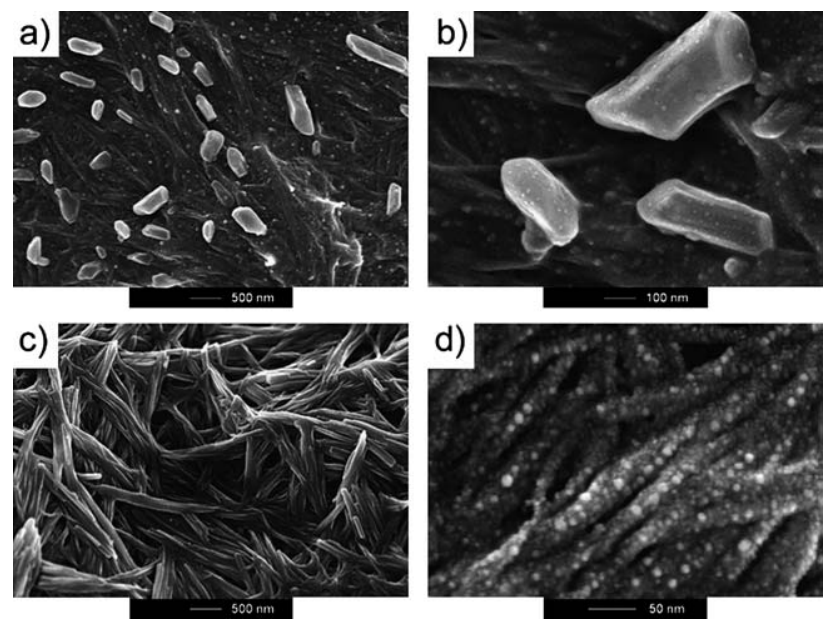

Fig. 5 SEM images of the gels after mineralization. (a, b) Gel with pure $\mathbf{1},(\mathrm{c}, \mathrm{d})$ gel with pure $\mathbf{2}$. 
growth modifiers. This is not surprising, as thioethers and thiols are known to interact with silver particles, ${ }^{21}$ and the thioether is therefore most likely the unit controlling silver nanoparticle growth on the fibers. Removal of the strong silver-sulfur interactions leads to a system, which allows for much less control over the mineralization process, and the entirely hydrophobic peptide 1 will lead to crystal growth, which is essentially unrestricted by strongly interacting moieties.

More detailed SEM and transmission electron microscopy (TEM) investigations show that some of the particles formed at different ratios of $\mathbf{1}$ and $\mathbf{2}$ have quite complex morphologies. Fig. 6 shows that, besides the $c a .9 \mathrm{~nm}$ particles and the large particles discussed above, more complex particle morphologies also exist. With decreasing content of $\mathbf{2}$, plates are increasingly observed, including plates with holes that have presumably formed via fusion of separately grown plate-like crystals. Furthermore, larger spheres, sometimes organized in chains, are observed. It is not clear to date, whether the chain-like organization is due to some drying effect on the TEM grid or due to some (invisible) peptide scaffold, which is still present. Finally, at contents below ca. $25 \%$ of 2 , we also observe what appears to be band-like elements, which, interestingly, are single crystalline particles, as is evidenced by electron diffraction of several samples (Fig. 6e, f).

Fig. 7 shows additional SEM images of samples grown at contents of 2 between 25 and $10 \%$. These particles often appear to have been covered with a second generation of smaller particle or particles with a "raspberry" morphology. We currently explain these features with heterogeneous nucleation on already existing silver particles (apparently mostly plates), which seems
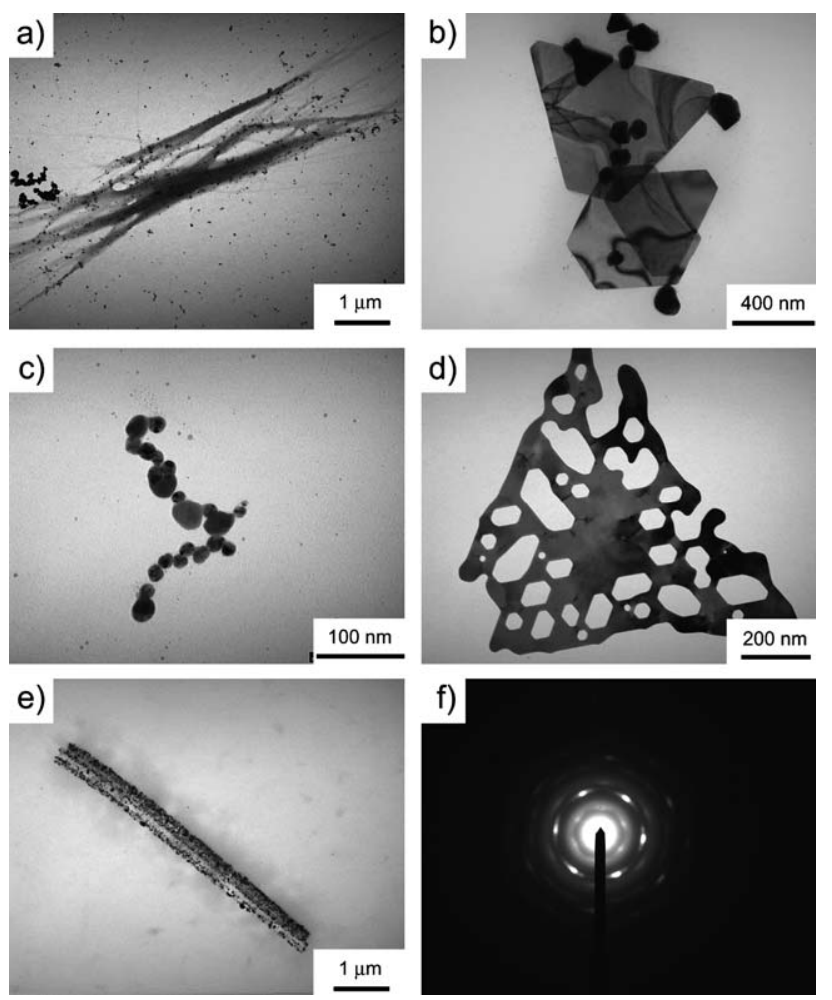

Fig. 6 TEM images of select peptide-nanoparticle aggregates. (a) $100 \%$ of $\mathbf{2}$, (b, c) $50 \%$ of $\mathbf{2}$, (d, e) $0 \%$ of $\mathbf{2}$, (f) electron diffraction pattern of the sample shown in (e).
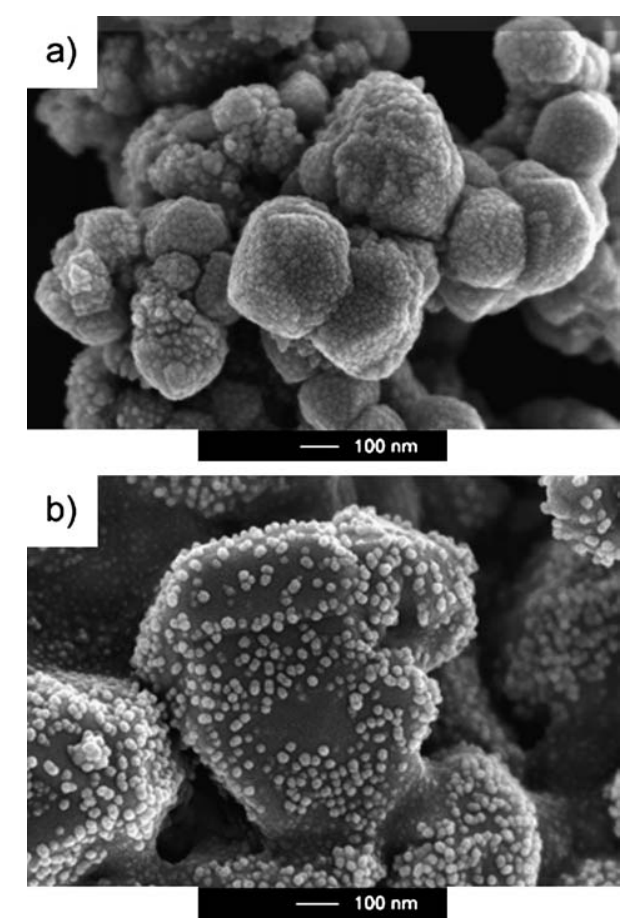

Fig. 7 SEM images of select silver nanocrystals. (a) Sample precipitated with $85 \%$ of $\mathbf{1}$, and (b) sample precipitated with $80 \%$ of $\mathbf{1}$ and $20 \%$ of $\mathbf{2}$. The sample shown in (a) has a raspberry-like morphology, and the sample shown in (b) clearly shows evidence for heterogeneous nucleation and growth on pre-existing silver plates or larger crystals.

to be energetically more favorable than further nucleation on the peptide fibers. We speculate that in the first deposition process, where the larger particles (Fig. 7b) form, nucleation and growth is preferred at locations with a high local concentration of the thioether moiety, that is, with a high concentration of 2. As a result, further nucleation and growth at other locations may be less favorable than heterogeneous (epitaxial) nucleation and growth on existing silver crystals.

In summary, SEM and TEM show that there is a transition from pure ca. $9 \mathrm{~nm}$ spheres at $100 \%$ of 2 (Fig. 5c, 5d and 7a) to samples containing the same spheres along with plates and larger spheres (Fig. 7b, c) at 50\% of $\mathbf{2}$. A further decrease of the content of $\mathbf{2}$ yields samples containing the small spheres, plates (occasionally with quite complex "holey" triangular or ribbon-like shapes) between 25 and $0 \%$ of 2 (Fig. $5 \mathrm{a}, 5 \mathrm{~b}, 7 \mathrm{~d}$, $7 \mathrm{e})$. In the same regime, we also often observe particles that appear to have been covered with a second generation of smaller particle or particles with a "raspberry" morphology. This can be explained by secondary nucleation and growth, which is preferred over growth on predominantly oligovaline fibers.

UV/Vis spectroscopy has been successfully used for the characterization of nanoparticle shapes and sizes, including silver particles. ${ }^{22-24} \mathrm{Fig} .8$ shows a representative UV/Vis spectrum of silver particles isolated from a sample containing $50 \%$ of $\mathbf{1}$ and $50 \%$ of $\mathbf{2}$. Essentially, all spectra only exhibit two to three very broad bands or shoulders. The fact that the bands are broad indicates that the silver particles created here are not very homogeneous in size.

Fitting of the UV spectra with Gaussian profiles, however, shows that the spectra are composed of up to seven overlapping 


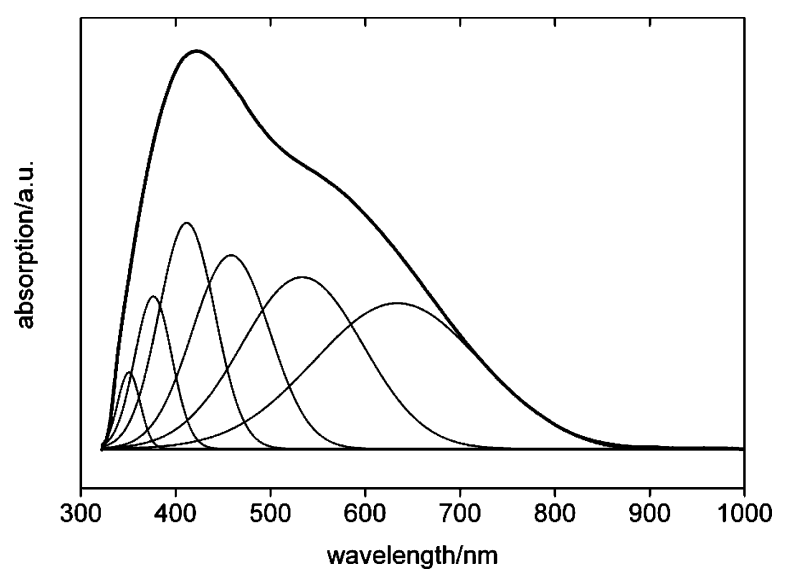

Fig. $8 \mathrm{UV} / \mathrm{Vis}$ spectrum of particles isolated from a sample containing $50 \%$ of $\mathbf{1}$ and $50 \%$ of $\mathbf{2}$ dissolved in methanol.

bands. The bands at $340-355 \mathrm{~nm}, 360-385,400-430$, and $455-$ $490 \mathrm{~nm}$ are attributed to overlapping peaks from scattering and plasmon resonances of the silver particles. ${ }^{22,23}$ These bands vary from sample to sample, which can again be explained by the presence of particles with different sizes and shapes. Bands between 525 and $575 \mathrm{~nm}$ can be attributed to distorted nanoparticles (bent plates or particles with distortions in the crystal lattice). If the amount of $\mathbf{2}$ is $75 \%$ or lower, two bands at around 525 and $660 \mathrm{~nm}$ are found. The former is again assigned to distorted particles and the latter band is due to the presence of (truncated) triangular nanoparticles. ${ }^{22}$

A further decrease of the fraction of $\mathbf{2}$ in the gels leads to another broad peak between 630 and $665 \mathrm{~nm}$, which can be assigned to the formation of polygon (twinned) crystals and triangular particles. ${ }^{23,25}$ Samples grown in gels containing only $25 \%$ of 2, exhibit another broad band at around $920 \mathrm{~nm}$. This band has earlier been assigned to a self-assembled raspberrylike structure or silver nanowires. ${ }^{23}$ Without 2, the particles behave spectroscopically as bulk material, although SEM and TEM show that these samples contain nanoparticles as well. Essentially, UV spectroscopy provides evidence that the mineralized gels contain particles of a diverse size and shape, which is consistent with SEM and TEM, see Fig. 6 and Fig. 7. Table 1 summarizes the absorption band positions obtained after deconvolution using Gaussian profiles.

Fig. 9 shows X-ray patterns of some mineralized gels. The patterns again exhibit more and sharper peaks as the fraction of $\mathbf{2}$ increases. This shows that the integrity of the peptide fibers is unaffected by the mineralization process, although slight shifts in the peak positions indicative of minute changes are found. XRD therefore confirms IR spectroscopy, Fig. 4, which shows that overall the peptide fibers do not change upon mineralization.

Table 1 UV bands determined from Gaussian fitting.

\begin{tabular}{ll}
\hline $\mathrm{wt} \%$ of $\mathbf{2}$ in the gel fibers & Band position $/ \mathrm{nm}$ \\
\hline 100 & $352,379,416,472,559,(977$, weak) \\
75 & $355,385,428,490,573$ \\
50 & $350,376,411,458,533,633$ \\
25 & $342,363,401,456,525,663,924$ \\
0 & No absorption detected \\
\hline
\end{tabular}
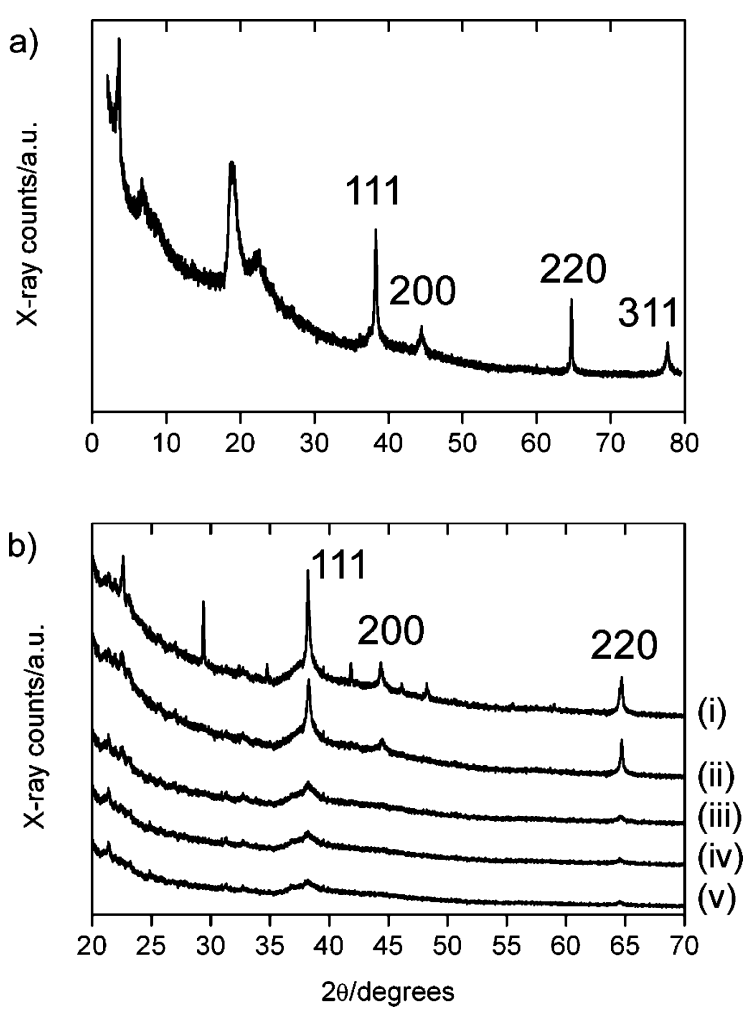

Fig. 9 (a) XRD pattern of a mineralized gel with $50 \%$ of 1 and $50 \%$ of 2. Although there are slight shifts in the peak positions compared to the control sample, the signal of the peptide fibers is not affected by the mineralization. (b) XRD patterns of gels mineralized with silver. Magnified view of the area showing the Ag reflections. (i) pure 1, (ii) $75 \%$ of 1 and $25 \%$ of $\mathbf{2}$, (iii) $50 \%$ each, (iv) $25 \%$ of $\mathbf{1}$ and $75 \%$ of $\mathbf{2}$, and (v) pure $\mathbf{2}$. The unlabeled reflections are from the peptide fibers.

Furthermore, XRD confirms the presence of metallic silver as additional reflections between 20 and 80 degrees $2 \theta$ can be assigned to silver (JPCPS 04-0783). At high fractions of $\mathbf{2}$ in the fibers, the silver reflections are broad. They become increasingly narrow, as the fraction of $\mathbf{2}$ decreases. XRD therefore shows a transition from silver nanoparticles with pure 2 to rather well-crystallized particles with pure $\mathbf{1}$. This indicates that the interaction of the peptide $\mathbf{2}$ with the growing silver crystals is much stronger than with peptide 1. XRD therefore supports SEM, TEM, and UV data showing that a direct tuning of the interaction between the peptide and the growing particles is possible with our gels.

The relative intensities of the reflections allow for a qualitative analysis of the structure-directing properties of $\mathbf{2}$, although they may contain some experimental error due to preferred orientation effects of, for example, the silver plates observed in the TEM. As long as $\mathbf{2}$ is present in the fibers in large amounts (over 50\%), all reflections are broad. The (200) reflection is not observed in these XRD patterns, presumably due to the fact that the peak is too broad to be detected. This indicates the presence of very small particles consistent with TEM. The presence of small isotropic particles is further supported by the (220)/(111) intensity ratio, which is 0.25 . This value is equal to that reported for bulk silver (0.25, JPCPS 04-0783). This indicates that the silver particles have a roughly isotropic distribution and orientation in 
the mineralized fibers without any preferential orientation. This is also again consistent with SEM and TEM data showing that most of the silver particles formed in the presence of high fractions of 2 are spherical and have a small diameter.

At $50 \%$ of 2 , the (200) reflection appears (although it is still very broad and weak). Again the (220)/(111) ratio is 0.25 to 0.28 , which is consistent with roughly spherical silver particles without preferred orientation. However, the (200)/(111) intensity ratio is 0.18 , which is much lower than the expected value of 0.4 . This indicates that here, there are also other particle shapes present in the sample. This is again consistent with the TEM data, which show the appearance of plate-like particles. With pure 1, the (200)/ (111) intensity ratio increases to 0.29 (expected 0.4 ), while the (220)/(111) ratio of 0.23 is again close to the expected value of 0.25 .

Overall, the $(220) /(111)$ ratio is always the same within the experimental error, regardless of the fiber composition. However, with increasing contents of $\mathbf{1}$, the $(200) /(111)$ ratio increases from inexistent ((200) absent) to a value closer to what it should be for an isotropic sample. We currently interpret this behavior as due to the much weaker interaction of $\mathbf{1}$ with the growing crystals. As a result of this weaker interaction and the absence (or low concentration) of a growth inhibitor like the thioether, the particles grow bigger. Crystallographically, their structure is closer and closer to bulk silver with increasing content of $\mathbf{1}$.

Table 2 summarizes the structures of the non-mineralized and the mineralized gels. Essentially, Table 2 shows that the scaffold self-assembly is conserved in the non-mineralized and mineralized stage. Moreover, UV-Vis, PXRD, and electron microscopy show the transition from silver nanoparticles to (almost) bulk metal properties as the amount of $\mathbf{2}$ decreases.

\section{Peptide-silver interactions}

To further quantify the interactions of the peptides with the growing silver particles, we have performed X-ray photoelectron spectroscopy (XPS) experiments on both peptides deposited on silver wafers. This system serves as a model for the peptide-silver nanoparticle interaction at the molecular scale and provides information about the binding modes of $\mathbf{1}$ and $\mathbf{2}$ to silver.

Fig. 10 shows silver and sulfur XPS spectra of $\mathbf{2}$ on a silver wafer. All signals (including carbon, oxygen, and nitrogen) a)

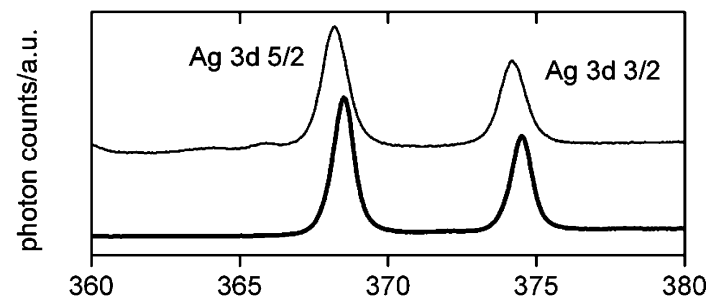

b)

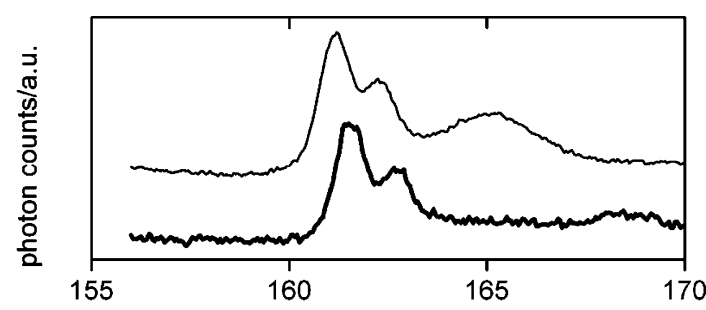

c)

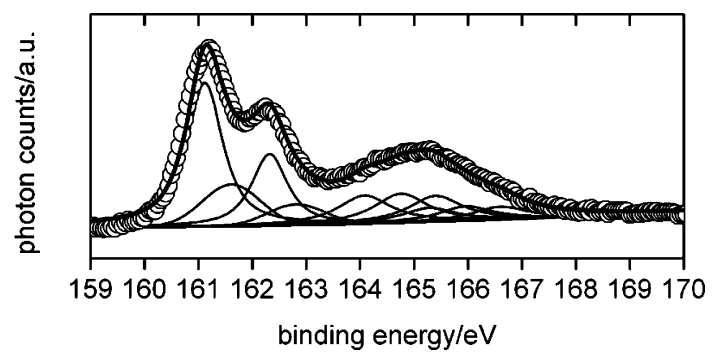

Fig. 10 XPS spectra of peptide 2 deposited on a silver wafer. (a) Silver $3 \mathrm{~d}_{5 / 2}$ and $3 \mathrm{~d}_{3 / 2}$ peaks. (b) Sulfur $2 \mathrm{p}_{1 / 2}$ and $2 \mathrm{p}_{3 / 2}$ peaks. Bold lines are samples deposited for ten minutes and thin lines are from samples deposited for two hours. (c) Deconvolution of the sulfur peaks of an XPS spectrum recorded for a sample exposed for 10 minutes. Open symbols are the experimental data, thick line is the peak sum from deconvolution and thin lines are the individual components of the deconvoluted spectrum.

have a full width at half maximum (FWHM) of around $1 \mathrm{eV}$, which is rather broad. The line broadening suggests that the peptides adopt a variety of conformations on the surface, which in turn indicates that there is no (highly) preferred orientation or interaction of the peptide with the surface. The silver $3 \mathrm{~d}_{5 / 2}$ and $3 \mathrm{~d}_{3 / 2}$ peaks do not vary with immersion time of the wafer and

Table 2 Structure of the non-mineralized gels, the mineralized gels, and silver nanoparticles in dependence of fraction of peptide 2.

\begin{tabular}{|c|c|c|c|c|c|}
\hline Percentage of $\mathbf{2}$ & $0 \%$ & $25 \%$ & $50 \%$ & $75 \%$ & $100 \%$ \\
\hline $\begin{array}{l}\text { XRD of the gels before } \\
\text { mineralization }\end{array}$ & Amyloid & Amyloid & Amyloid & Amyloid & Amyloid \\
\hline $\begin{array}{l}\text { UV-VIS after } \\
\text { mineralization }\end{array}$ & Bulk & $\begin{array}{l}\text { Raspberry structure } \\
\text { or silver nanoparticles }\end{array}$ & Triangles & Nanoparticles & Nanoparticles \\
\hline $\begin{array}{l}\text { IR structure after } \\
\text { mineralization }\end{array}$ & $\begin{array}{l}\beta \text {-Sheet no } \\
\text { oxidation }\end{array}$ & $\beta$ sheet no oxidation & $\beta$-Sheet no oxidation & $\beta$-Sheet no oxidation & $\beta$-Sheet no oxidation \\
\hline $\begin{array}{l}\text { XRD of the gels after } \\
\text { mineralization (silver) }\end{array}$ & Bulk & Distorted & Preferential orientation & $\begin{array}{l}\text { Nanoparticles }+ \\
\text { preferential orientation }\end{array}$ & $\begin{array}{l}\text { Nanoparticles }+ \\
\text { preferential orientation }\end{array}$ \\
\hline TEM & Large particles & $\begin{array}{l}\text { Triangles and related } \\
(\text { size }>100 \mathrm{~nm})\end{array}$ & Triangle and related & Triangles and related & Nanoparticles \\
\hline SEM & Large particles & $\begin{array}{l}\text { Triangles and related } \\
(\text { size }>100 \mathrm{~nm})\end{array}$ & Triangle and related & Triangles and related & Nanoparticles \\
\hline
\end{tabular}


are in all cases located at around 368.25 and $374.25 \mathrm{eV}$, which is indicative of an oxidized metallic silver surfaces. ${ }^{26-28}$

Unlike the silver peaks, the S 2 p signals vary slightly. After deconvolution, all spectra show a peak at around the $S 2 p_{3 / 2}$ energy of $161.15 \mathrm{eV}$, which is indicative of $\mathrm{S}^{2-} \cdot{ }^{29}$ As the same signal is also present in the control samples (samples immersed in hot methanolic solution without the peptide), this signal may be due to some contamination or to degradation of $\mathbf{2}$ on the surface during the peptide deposition.

The $2 p_{3 / 2}$ peak at $161.54 \mathrm{eV}$ is due to thiols chemically bound to the silver surface. This is not surprising as silver surfaces can cleave thioethers, in particular S-benzyl ethers. ${ }^{30,31}$ The signal at around $163.80 \mathrm{eV}$ is attributed to chemisorbed thioether. Signals for $2 \mathrm{p}_{1 / 2}$ at $164.7 \mathrm{eV}$ and $166.0 \mathrm{eV}$ arise from thioether physisorbed on top of peptides bound to the surface, respectively. The $2 \mathrm{p}_{3 / 2}$ peak at $168.21 \mathrm{eV}$ is only present in the samples immersed for 10 minutes. This peak arises from oxidized forms of the thioether, most likely upon exposition to air.

In summary, XPS provides evidence of a variety of sulfur species that can form with silver. XPS supports the observation that peptide $\mathbf{2}$ is an efficient growth modifier because it provides a sulfur atom, which can be present as a chemisorbed or physisorbed thioether or via the in situ formation of a thiol. As IR spectroscopy and XRD of the gels after mineralization show that the gels remain intact after mineralization, XPS provides evidence that there is still the possibility of a reaction of the peptide with the silver on the fiber surface. This reaction can include rather drastic processes like thioether cleavage and generation of free thiol or thiolate and eventually silver thiolate bonds.

XPS clearly shows that there is an interaction of the sulfur atom of peptide $\mathbf{2}$ with the silver surface. Surface enhanced Raman spectroscopy (SERS) provides additional insight into the surface orientation and binding mode of the peptides with the surface. ${ }^{32-35}$ Fig. 11 shows SER spectra recorded from both peptide $\mathbf{1}$ and $\mathbf{2}$ on a silver surface. SERS shows that peptide $\mathbf{1}$ is randomly oriented on the silver surface. Spectra recorded at different locations of the wafers yield the same spectra, but the relative intensities are quite different between measurements. These intensity variations are most obvious for the benzyl ring vibrations at 2900 to $3000 \mathrm{~cm}^{-1}\left(\nu_{\mathrm{C}-\mathrm{H}}\right.$, ring and aliphatic residue, undistinguished) and at $1007 \mathrm{~cm}^{-1}$ (ring-breathing vibration), the amide vibrations at $1664 \mathrm{~cm}^{-1}\left(\nu_{\mathrm{C}=\mathrm{O}}\right.$, amide $)$, the carbonyl vibrations at $1747 \mathrm{~cm}^{-1}\left(\nu_{\mathrm{C}=\mathrm{O}}\right.$, methyl ester $)$, and the aliphatic chain vibrations at $1336 \mathrm{~cm}^{-1}\left(\delta_{\mathrm{CH} 3}\right)$. SERS therefore shows that the peptide $\mathbf{1}$ is adsorbed on the surface. However, the interaction of the peptide with the surface is not uniform, but there are several groups, including the amide, the ester, and the benzyl groups, which contribute to the binding.

In contrast to $\mathbf{1}$, all spectra recorded for $\mathbf{2}$ are essentially identical, including the relative band intensities. The spectra exhibit a broad band at $660 \mathrm{~cm}^{-1}$ attributed to $\nu_{\mathrm{C}-\mathrm{S}}$ in thioethers. A further band at $650 \mathrm{~cm}^{-1}$ is also attributed to $\nu_{\mathrm{C}-\mathrm{S}}$ in thioethers. This band indicates that some of the thioether is present as a chemisorbed thioether or in a cleaved stage, as thiol. ${ }^{30}$ In the current case, however, SERS does not allow for a unambiguous distinction of thiol $v s$. chemisorbed thioether because of a broad emission peak at 200 to $320 \mathrm{~cm}^{-1}$. This peak is assigned to either an $\mathrm{Ag}-\mathrm{O}$ bond from air oxygen or $\mathrm{Ag}_{2} \mathrm{O}$, which may form upon air exposition of activated surface, ${ }^{36} \mathrm{a} \mathrm{Ag}-\mathrm{N}$ bond from the
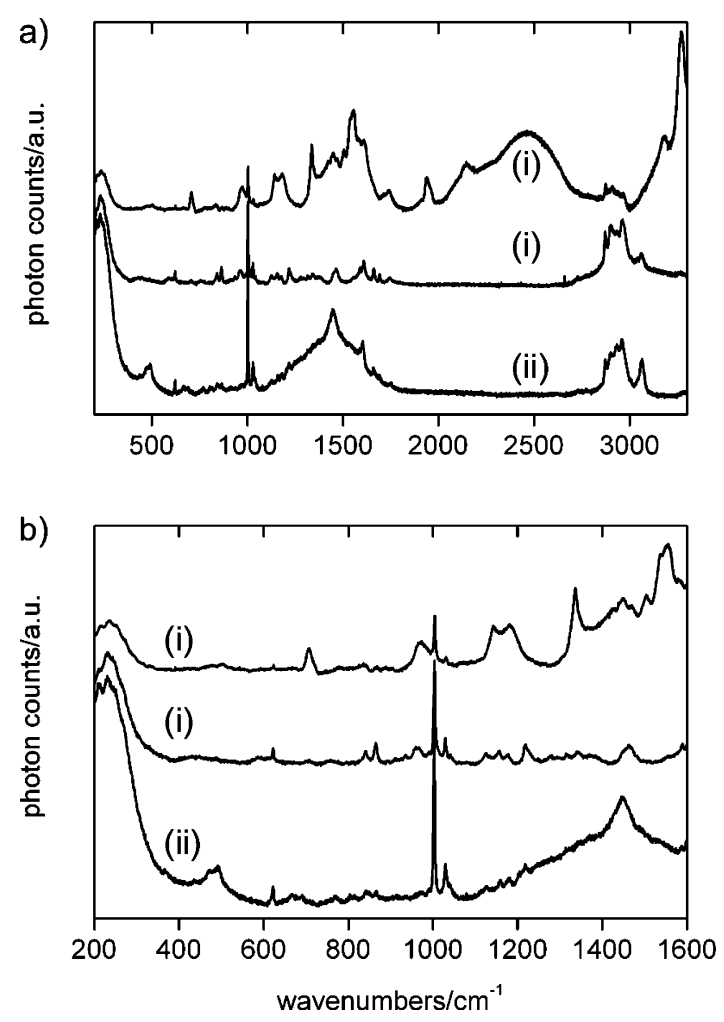

Fig. 11 (a) SER spectra of a silver surface (i) coated with 1, and (ii) coated with 2. (b) Magnified view of the lower wavenumber region.

peptide, ${ }^{37}$ or, less likely, from a sulfur containing contamination. This peak overlaps with the position of the $\nu_{\mathrm{Ag}-\mathrm{S}}$ vibration, ${ }^{30}$ which would confirm the presence of a thiol bond. In summary, therefore, SERS confirms the XPS data, although SERS cannot confirm the generation of some thiol in the sample.

A SERS signal is observed if the electric field vector at the silver surface is collinear with the polarizability vector of a bond of the adsorbed molecule. If the field vector and the polarizability vector, however, are perpendicular to one another, there is no emission in the spectra. As a result, the bands at 975, 1000,1586 , and $2935 \mathrm{~cm}^{-1}$ clearly show that peptide 2 binds to the silver via the carbamate benzyl ring and the thioether benzyl group. The presence of the signal at $1350 \mathrm{~cm}^{-1}$ further shows that the alkyl groups of the peptide are perpendicular to the surface. In contrast, the absence of a band over $1600 \mathrm{~cm}^{-1}$ shows that the amide moieties are parallel to the surface, because there is no SERS signal from this part of the molecule. This is consistent with the interpretation of the broad emission peak at 200 to $320 \mathrm{~cm}^{-1}$, which was assigned to a $\mathrm{Ag}-\mathrm{O}$ or $\mathrm{Ag}-\mathrm{N}$ bond. While the $\mathrm{Ag}-\mathrm{O}$ was assigned to $\mathrm{Ag}_{2} \mathrm{O}$ on the surface via XPS, the $\mathrm{Ag}-\mathrm{N}$ bond is due to bonding between the peptide nitrogens and the silver wafer.

Overall, SERS indicates that the peptide lies flat on the silver surface and does not form (perpendicular) brushes. This is in stark contrast to peptide $\mathbf{1}$, which adopts a variety of conformations on the surface, although it also contains benzyl and amide groups that could in principle lead to the same organization. However, SERS indicates that the second benzyl group and the sulfur atom introduced via the thioether is a key part for uniform peptide-silver interactions. 


\section{Interaction of silver ions with peptide 2}

We have shown above that the peptide $\mathbf{2}$ is a much stronger growth modifier for silver nanoparticles than 1. In part this is due to the strong interaction of the thioether or thiol moiety, which is shown by XPS to directly interact with silver. Furthermore, SERS provides evidence that peptide $\mathbf{2}$ also interacts with silver via the additional benzyl group from the thioether side chain. A further point of interest is how and how strongly the $\mathrm{Ag}^{+}$ions interact with the peptide fibers prior to nucleation and growth of the particles. This question has been addressed via ${ }^{13} \mathrm{C} \mathrm{NMR}$ and $\mathrm{UV} / \mathrm{Vis}$ titration.

Fig. 12 shows UV/Vis spectra and UV/Vis titration data of a 1 $\mathrm{mM}$ solution of $\mathbf{2}$ in DMSO with a $1 \mathrm{mM}$ solution of $\mathrm{AgNO}_{3}$ in DMSO. The spectra of the peptide and silver nitrate solutions quite strongly overlap. This indicates that the data may have a rather large error. Nevertheless, Fig. 12 shows that the absorption spectra change as the peptide $\mathbf{2}$ is titrated with silver nitrate. All bands at 290, 314, and $340 \mathrm{~nm}$ slowly increase in intensity until an $\mathrm{Ag} /$ peptide ratio of $1: 1$ is reached. Thereafter, the band at $314 \mathrm{~nm}$ levels off to a constant value and the bands at 290 and $340 \mathrm{~nm}$ slowly decrease again. These data therefore indicate a $1: 1 \mathrm{Ag}$-peptide complex.

Fig. 13 shows that addition of $\mathrm{AgNO}_{3}$ gradually shifts the ${ }^{13} \mathrm{C}$ signal of carbons in the $\alpha$ position of the sulfur in $\mathbf{2}$ from $c a$. 36.1 to $37.2 \mathrm{ppm}$ until at 2 equivalents of $\mathrm{Ag}^{+}$no further shift is observed. Control experiments with $\mathrm{NaNO}_{3}$ show that $\mathrm{Na}^{+}$ does not lead to a shift of the respective signals. This confirms that the shift is due to a true $\mathrm{Ag}^{+}$-peptide interaction and not

a)
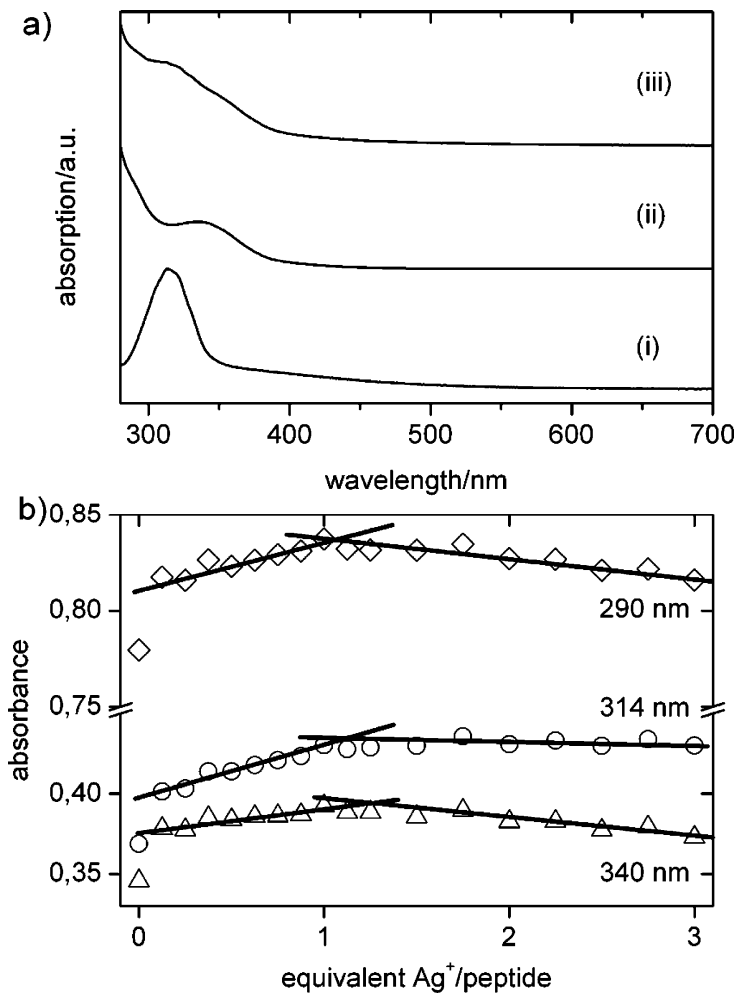

Fig. 12 UV/Vis spectra and titration data. (a) UV/Vis spectra of (i) $\mathrm{AgNO}_{3}$ in DMSO, (ii) peptide 2 in DMSO, and (iii) mixture of $\mathrm{AgNO}_{3}$ and peptide 2 in DMSO. (b) UV/Vis titration data recorded at 290, at 314 , and at $340 \mathrm{~nm}$.
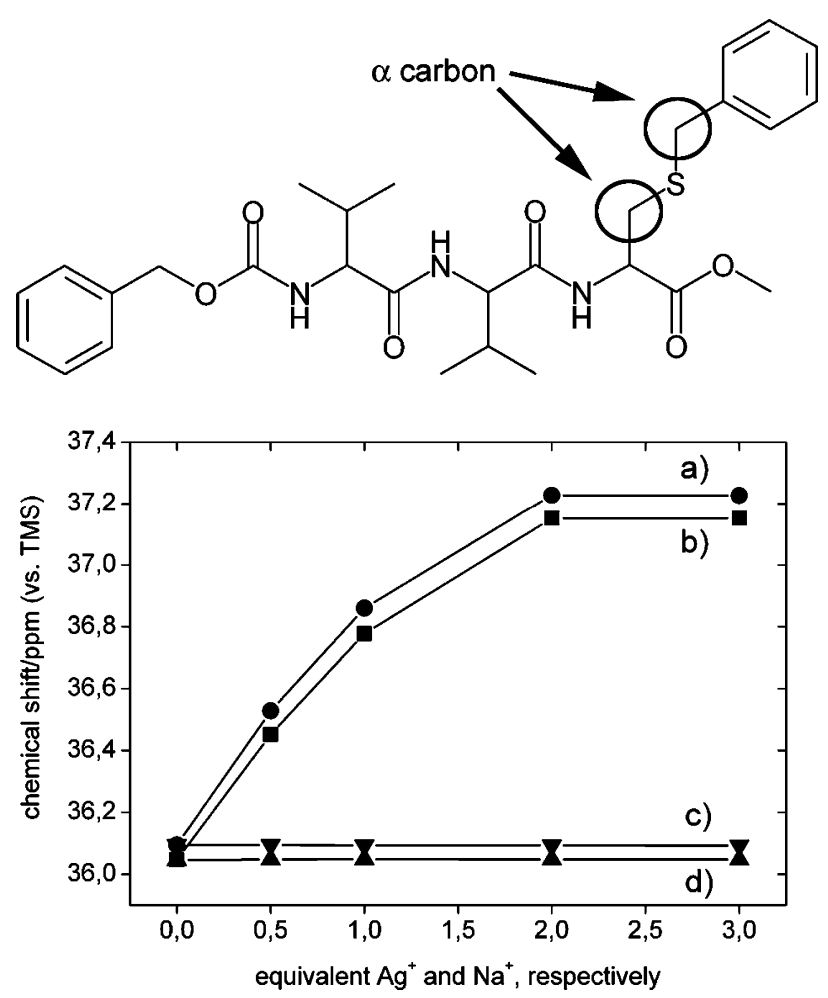

Fig. $13{ }^{13} \mathrm{C}$ NMR titration of carbon atoms in the $\alpha$ position of the sulfur in 2 in $\mathrm{d}_{6}$-DMSO. (a, b) Shift of the two $\alpha$ carbon atoms upon titration with $\mathrm{AgNO}_{3}$. (c, d) Shift of the two $\alpha$ carbon atoms upon titration with $\mathrm{NaNO}_{3}$. The position of the $\alpha$ carbons is shown in the molecular structure of peptide $\mathbf{2}$.

an effect of ionic strength. Furthermore, the fact that the shift is observed for the carbon atoms next to the sulfur clearly indicates that the interaction as determined from UV titration is a silver-sulfur interaction. UV/Vis and ${ }^{13} \mathrm{C}$ NMR therefore show that there is an interaction between the silver ions and the thioether moiety already prior to nucleation and growth of the silver nanoparticles. The discrepancy between the UV/Vis and the NMR data in terms of the number of silver equivalents is to date unresolved. However, further NMR studies also show that the benzyl ring of the thioether, but not the benzyl group of the Z-group, interacts with the silver cations, most likely via cation $-\pi$ interactions. This suggests that the binding of the silver cations to the peptides can occur via multiple binding modes, which makes a quantitative analysis rather difficult.

Despite the discrepancy between NMR and UV/Vis data, it is possible to qualitatively describe the binding mode of a silver cation with the peptide. Three modes of interaction can be envisaged: (i) the cation- $\pi$ (arene) interaction via $\pi$ - or $\sigma$-binding modes (via employing a heteroatom) as described by Fukin et al. for alkali metals, ${ }^{38}$ (ii) the interaction of (poly)aromatic ligands via cation- $\pi$ (arene) interactions with silver, ${ }^{39}$ and (iii) the more classical complexation of silver by sulfur dithioethers. ${ }^{40,41}$ The sulfur atom certainly plays a key role, as the $\mathrm{Z}$ moiety does not interact with silver cation, even though it is structurally similar to the S-benzyl thioether. As a result, the mode of interaction of a silver cation with the peptide is likely based on a cation $-\pi$ arene interaction via $\pi$ - or $\sigma$-interaction modes with the assistance of the thioether as described in a comparable system by Fukin et al. ${ }^{38}$ 


\section{Discussion}

\section{Particle formation}

Peptide-controlled mineralization of silver particles has so far been achieved with redox-active peptides, most often based on tyrosine or tryptophan. They were either in solution or incorporated into gels. ${ }^{11-13,17}$ Histidine-rich peptides have also been used as scaffolds, but there, an additional reducing agent, sodium borohydride, was used. ${ }^{14,15}$ The major drawback of this approach is that the samples require extensive purification after synthesis. Both approaches using sodium borohydride and using redox-active peptides are therefore different from the current approach, which uses DMF as a reducing agent.

Avoiding an external reducing agent may seem an advantage, but the disadvantage is that the template (peptide) concentration, the silver ion concentration, and the reaction temperature are the only variables in the system. This allows for some control over nucleation and growth, but the use of an independent reducing agent offers many more possibilities for reaction tuning. For example, if the concentration of the reducing peptide is increased, also the amount of the peptide scaffold and therefore the internal surface, which interacts with the growing particles, changes. That is, there is no independent variation of both the scaffold and the reducing agent.

The current paper however shows that mixtures of two different peptides can in some cases be quite interesting for the fabrication and tuning of organic-inorganic composites. This is in particular true if one peptide is regarded (and designed) as a "structural" unit, which does not interact with the growing inorganic. In our case this would in a first approximation be the peptide 1. If however, the other peptide contains functional groups, for example thiols (that is, coordination or nucleation promoters) or alcohol moieties (that is, reducing agents) it is possible to combine a wide variety of functions in one self-assembling system. Because the peptides can be fabricated individually and combined later, mixtures of $\mathbf{1}, \mathbf{2}$, and a peptide containing e.g. tyrosine can be envisioned. The resulting gels would provide an interesting reactive scaffold for silver-peptide hybrid materials. As such, the current paper is just one example of such a modular peptide toolbox.

Proteins, which also provide control over the spatial organization of nucleation and growth, ${ }^{16}$ can be viewed as more complex varieties of our approach. That is, the peptides used here form a primitive, but still functional, "protein" scaffold for controlling silver mineralization. As XRD and IR do not show a clear segregation of both peptides within the fibers, mixed fibers of $\mathbf{1}$ and $\mathbf{2}$ can be viewed as a simplified large protein with statistically distributed sulfur moieties on the surface.

Earlier studies have mainly commented on the reduction mechanisms, which have been studied by exploiting the tryptophan or tyrosine fluorescence, ${ }^{11,12}$ or IR, solid state ${ }^{13} \mathrm{C}$ NMR, and UV/Vis spectroscopy. ${ }^{11,17}$ The present study also reports on the interactions of the peptides with the silver surface. Based on the current data, the following model can be derived.

NMR and UV/Vis titrations provide evidence for an association of the silver cations with the sulfur atom in the thioether. This is the first step required for controlled particle nucleation and growth and similar surface-enrichment processes close to peptide moieties have been described for histidine, methionine, cysteine, tryptophan, and arginine-rich peptides. ${ }^{2,15,16,28,42}$ Once nucleation has occurred and the silver colloids start forming, the outcome of the mineralization process is largely governed by the concentration of the thioether moieties on the peptide fiber surface, because the main interaction between the peptides and the growing silver particles occurs via bonding of the thioether (thiol), amide, and benzyl groups of the peptide, as evidenced by XPS and SERS.

The main interaction is a silver-sulfur interaction. This approach therefore adds another type of functional group to the peptide family, which can be used besides amines, free thiols, and unspecific adsorption of the peptides to silver ${ }^{11-16}$ for nucleation and crystallization control. As the $\mathrm{Ag}-\mathrm{S}$ interaction is quite strong, the peptide fibers with high contents of $\mathbf{2}$ are efficient growth modifiers and hence these fibers are covered with silver particles of $c a .9 \mathrm{~nm}$ in diameter. The particles are trapped and further growth (for example via Ostwald ripening) is prevented. Because of the strong binding of the silver to the sulfur, the resulting particles have a rather low mobility and essentially remain attached to the location where they initially form.

As the content of $\mathbf{2}$ in the fibers decreases to below $50 \%$, the interaction between the silver ions, silver particles, and the peptide fibers decreases. Nucleation in solution (that is, homogeneous nucleation) is still not favorable due to the presence of a high internal surface provided by the peptide fibers. However, the surface energies of the peptide fibers change, as the thioether is increasingly removed. Assuming that the particles still form via heterogeneous nucleation, the formation of large particles observed with low contents of $\mathbf{2}$ can be explained with Ostwald ripening. Initially there is a silver-peptide interaction, as evidenced by ${ }^{13} \mathrm{C}$ NMR. However, after nucleation, the interaction between the particles and the peptide fibers is too weak to completely suppress Ostwald ripening and rather large crystals with various shapes form.

As the content of $\mathbf{2}$ decreases below 25\%, nucleation and growth is largely governed by the hydrophobic surface of the peptide fibers. Sulfur-containing peptides still interact with the growing clusters. As the sulfur-containing moieties are being covered by the growing large crystals, further reduction of silver ions leads to growth according to a model developed by Naik et al. ${ }^{43}$ According to this model, peptides modify crystal growth by allowing accumulation of the silver atoms on the lowest surface-energy face where the peptide is accumulated. Furthermore, the surface energy $\gamma$ of different crystal faces in facecentered cubic metals is lower for 111 faces than for others $\left(\gamma_{\{110\}}>\gamma_{\{100\}}>\gamma_{\{111\}}\right){ }^{44}$ As a result, there is a preferential interaction of the peptide fibers with the 111 faces. Therefore, growth will have to occur along other crystallographic axes and the resulting anisotropic particles will have large 111 faces. This is evidenced by TEM and electron diffraction data, consistent with existing theories of crystal growth. ${ }^{44}$

Finally, the peptides not only control the growth of the particles, they also control their organization. The presence of the thioether moieties on the fiber surface provides a simple, yet efficient, scaffold because the strong silver-sulfur interaction defines the location of nanoparticle nucleation and growth and the orientation of the particles on the fibers. This is again similar to earlier reports in the literature. Naik et $a l^{43}$ have shown that peptides interact with lower energy surface to influence the shape of the particle. Mo et al. ${ }^{16}$ have shown that silver colloids can be organized on a protein like scaffold. 


\section{Potential of the approach}

The current approach to silver (and potentially other metal)peptide hybrid structures has a few advantages over other "bioinspired" systems reported in the literature. First, our peptides are, in principle, fully recyclable because they are not involved in the silver colloid formation (although there is some evidence of thioether cleavage from XPS). This is unlike earlier examples where the peptides are mostly oxidized during particle formation and could therefore not be reused. ${ }^{11,13,45}$ Here, the peptide can be separated from the colloidal silver by dissolution of the composite in methanol. After centrifugation and solvent evaporation, the peptide can be recovered.

Secondly, gels have already been proposed for the organization of nano-objects via chemical interaction ${ }^{13,16,17}$ or passively (i.e. with or without limited chemical interactions) by containment of the silver particles in the solvent cavities of a gel. ${ }^{46}$ Silver nano-objects are currently under intensive investigation not only for their optical properties but also for their peculiar electronic properties. ${ }^{47}$ It is thus of interest to have access to a methodology where the nanoparticles can be embedded in a gel. In particular, gels which not only prevent uncontrolled particle aggregation but can also be easily processed, are of interest. Gels like the ones presented here could find use as filter or optically active material if included properly in a device. However, further work on our system is required to form a true 1-D infinite helical chain of nanoparticles on the peptide fiber surface.

Furthermore, it is of interest to evaluate the potential of our gels for the synthesis of hollow silver tubes, similar to the larger anatase materials reported in a previous report. ${ }^{18}$ Because of their peculiar shape and physical properties, such materials could, for example, be used in optical waveguide anistropically conducting gels, and, on a more fundamental level, these advanced materials could be used to systematically study correlations between structure and physical properties. ${ }^{47-50}$

More interestingly, our peptide scaffold is (with only 3 amino acids) a much simpler scaffold than many others, that is, it is easy to fabricate on a large scale. Nevertheless it is possible to prepare gels that act as templates for hybrid material formation. XPS and SERS also suggest that under certain conditions it might be possible to generate surfaces with a relatively high order. Possibly, 2-D and 3-D structures similar to protein arrays ${ }^{16,17}$ may be fabricated, without the need to prepare highly complex bioengineered structures.

\section{Experimental}

\section{Peptide synthesis}

Amino acids were purchased from Bachem AG (Bubendorf, Switzerland) and chemicals from Fluka (Buchs, Switzerland). All chemicals were used as received. Z-L-Val-L-Val-OH and $\mathrm{Z}-(\mathrm{L}-\mathrm{Val})_{3}-\mathrm{OMe} 1$ was obtained as described before. ${ }^{18}$

\section{Synthesis of ZVVC(S-Bzl)OMe 2}

$1.4 \mathrm{~mL}(10.3 \mathrm{mmol})$ of isobutyl chloroformate were added to a salt-ice cooled solution of $\mathrm{Z}-\mathrm{L}-\mathrm{Val}-\mathrm{L}-\mathrm{Val}-\mathrm{OH}$ (3.0 g, 8.6 $\mathrm{mmol})$ and 4-methylmorpholine $(1.7 \mathrm{~mL}, 14.6 \mathrm{mmol})$ in $25 \mathrm{~mL}$ of acetonitrile under argon. The reaction mixture was stirred for two minutes. Then $2.7 \mathrm{~g}(10.3 \mathrm{mmol})$ of L-cysteine-S-benzyl methyl ester hydrochloride and $1.7 \mathrm{~mL}(14.6 \mathrm{mmol})$ of 4-methylaminomorpholine were added. After 15 minutes, the cooling was stopped and the solution was allowed to warm up to room temperature, upon which the solution was stirred for 24 hours. The solvents were removed by rotary evaporation. The residue was dissolved in $200 \mathrm{~mL}$ of a mixture of chloroform and methanol $(3: 1)$. The organic solution was washed three times with $100 \mathrm{~mL}$ of a saturated hydrogen carbonate-sodium chloride solution, and once with sodium chloride solution. Then 100 $\mathrm{mL}$ of methanol were added, and the solution was washed three times with $100 \mathrm{~mL}$ of a mixture of $10 \%$ citric acid and sodium chloride solution, and finally twice with a sodium chloride solution. The organic phase was dried with sodium sulfate, concentrated to dryness, and the residue was triturated with pentane to give a white to slightly yellowish solid (3.1 g, 65\%) after drying under vacuum overnight.

IR (neat, $\mathrm{cm}^{-1}$ ): 3284, 3080, 2950, 1741, 1686, 1638,1537, 1454, 1342, 1290, 1246, 1217, 1073, 1006, 990, 967, 921, 879, 863, 843, $808,770,755,738,696,660,609 .{ }^{13} \mathrm{C}$ NMR ( $\delta$ in ppm $v s$. TMS, $\mathrm{d}_{6}$-DMSO, $100 \mathrm{MHz}$, signals of all conformers in brackets): $172.24,171.82,171.77,\{157.10-156.95\}, 138.90,\{137.96-$ $137.88\}, 129.77,129.77,129.74,129.24,129.18,128.60,128.47$, $127.76,\{66.27-66.20\},\{61.15-61.10\},\{57.97-57.90\},\{52.92-$ $52.85\},\{52.62-52.42\},\{52.92-52.85\},\{52.60-52.46\}, 36.25$, $32.62,20.10,19.90,19.08$. ${ }^{1} \mathrm{H}$ NMR ( $\delta$ in ppm vs. TMS, $\mathrm{d}_{6}$-DMSO, $\left.400 \mathrm{MHz}\right): 8.46(\mathrm{~m}, 1 \mathrm{H}, \mathrm{H}$ amide $), 7.91(\mathrm{~m}, 0.3 \mathrm{H}$, $\mathrm{H}$ amide), 7.73 (m, 0.7H, $\mathrm{H}$ amide), 7.27 ( $\mathrm{m}, 11 \mathrm{H}, \mathrm{H}$ carbamate + cysteine benzyl ring + benzyl), $5.01 \mathrm{ppm}$ (s, 1H, benzylic), 4.99 ppm (s, 0.7H, benzylic), $4.45(\mathrm{~m}, 1 \mathrm{H}, \alpha$-Val-1), $4.27(\mathrm{~m}, 1 \mathrm{H}$, $\alpha$-Val-2), 3.96 (m, 1H, $\alpha$-Cys), 3.72 (m, 2H, benzyl Cys), 3.60 (m, 3H, methyl ester), 2.76 ( $\mathrm{m}, 1 \mathrm{H}, \beta$-cys), 2.64 (m, 1H, $\beta$-cys), $1.96(\mathrm{~m}, 2 \mathrm{H}, \beta$-Val-1 + $\beta$-Val-2), $0.85(\mathrm{~m}, 12 \mathrm{H}, \gamma$-Val-1 + $\gamma$-Val-2). Elemental analysis: calculated $\mathrm{C} 62.46, \mathrm{H} 7.05, \mathrm{~N}$ 7.53, O 17.21, S 5.75; measured C 62.52, H 6.95, N 7.55. FABMS: calculated $\mathrm{M}-\mathrm{H}^{+}=557$, measured $\mathrm{M}-\mathrm{H}^{+}=557$.

\section{Silver nanoparticle synthesis}

In a typical experiment, $25 \mathrm{mg}$ of $\mathrm{Z}-(\mathrm{L}-\mathrm{Val})_{3}-\mathrm{OMe} \mathbf{1}$ were mixed with $75 \mathrm{mg}$ of $\mathrm{Z}-(\mathrm{L}-\mathrm{Val})_{2}-\mathrm{Cys}(\mathrm{S}-\mathrm{Bzl})-\mathrm{OMe} 2$ in a vial. Then 1 $\mathrm{mL}$ of $n$-butanol and $100 \mu \mathrm{L}$ of dimethylformamide (DMF) were added. The vial was heated to 80 to $100{ }^{\circ} \mathrm{C}$, and as soon as the peptide was dissolved, $26 \mathrm{mg}$ of silver nitrate dissolved in $60 \mu \mathrm{L}$ of distilled water are added to the vial. The mixture was shaken for $30 \mathrm{~s}$, followed by rapid heating with a hotplate to $80^{\circ} \mathrm{C}$. Then the vial was closed and left untouched for 5 days.

\section{Spectroscopy}

${ }^{1} \mathrm{H}$ and ${ }^{13} \mathrm{C}$ NMR spectra were recorded on an Avance $400 \mathrm{MHz}$ NMR spectrometer. Infrared spectra were obtained from the neat samples on a Shimadzu FTIR 8300 with a Golden Gate ATR unit. Spectra were recorded from 300 to $4500 \mathrm{~cm}^{-1}$ with a resolution of $1 \mathrm{~cm}^{-1}$. FAB-MS spectra were taken on a Finnigan MAT 312. UV/Vis spectroscopy was performed in a quartz cuvette with an optical path length of $1 \mathrm{~cm}$ on a Perkin Elmer Lambda 25 or an Agilent 8453 using the same cuvette for the titration experiment. Data deconvolution was performed using 
Fytik and the Chemstation Agilent software was used to retrieve data values.

\section{Surface enhanced Raman scattering}

Silver wafers of $1 \times 1 \times 0.05 \mathrm{~cm}$ were degreased with acetone, dried with argon, and etched for $3 \mathrm{~min}$ in $3.5 \mathrm{M}$ nitric acid under stirring. ${ }^{51}$ The silver was dried with argon and immersed in a hot methanolic, approximately $1 \mathrm{mM}$ peptide solution. After 10 minutes, the wafer was removed from the solution, the excess of solution was removed by argon flushing, and the wafer was dried at $40{ }^{\circ} \mathrm{C}$ in a vacuum oven overnight. Microscopy was done with an Olympus BX $41(100 \times$ objective $)$ optical microscope coupled to a Labram HR800 Jobin Yvon Horiba Raman spectrometer with a $514 \mathrm{~nm}$ laser and a power of $5.20 \mathrm{~mW}$. The confocal hole was $400 \mu \mathrm{m}$ and the slit $150 \mu \mathrm{m}$.

\section{Microscopy}

Scanning electron microscopy was done on a Hitachi S-4800 operated at $10 \mathrm{kV}$. Samples were sputtered with $5 \mathrm{~nm}$ of platinum prior to imaging. TEM images were taken using an FEI Morgani 268D operated at $80 \mathrm{kV}$. Samples were deposited on carbon-coated copper grids and directly imaged after drying in air. Some samples were diluted prior to imaging to allow for better imaging conditions.

\section{X-Ray diffraction}

X-Ray patterns were measured at room temperature on a Stoe Stadi $\mathrm{P}$ diffractometer equipped with a curved germanium monochromator. $\mathrm{X}$-Ray radiation was $\mathrm{Cu} \mathrm{K} \alpha$ radiation and data analysis was done with OriginLab Origin 6.1.

\section{X-Ray photoelectron spectroscopy}

XPS was done on a VG ESCA Lab 220iXL with a Mg K $\alpha$ $(1253.6 \mathrm{eV})$ source. Take-off angle was $90^{\circ}$ and the pressure during measurements was $10^{-10}$ mbar. The silver wafer had dimensions of $c a .1 .5 \times 1.5 \times 0.05 \mathrm{~cm}$. Wafers were first degreased with acetone, then chemically etched three times with concentrated nitric acid, rinsed with distilled water, and finally dried with argon. The clean silver wafers were immersed in a rapidly stirred, hot methanolic solution of the peptides or in neat methanol for the control measurements. After ten minutes and two hours of immersing, the wafers were removed from the solution, the excess solution was removed by flushing the wafer with argon and the wafers were then dried overnight under vacuum at $40{ }^{\circ} \mathrm{C}$. Data analysis was done using Unifit 2006 (evaluation version) and XPSPEAKS 4.1.

\section{Conclusion}

In summary, we have introduced a simple tool for the controlled fabrication of peptide-silver nanoparticle hybrid fibers and gels with a pre-programmed silver nanoparticle size and shape. This study shows that the Brust-Shiffrin concept of nanoparticle size selection by metal ion-thiol ratio variation ${ }^{4,5}$ also works when the thiols or thioethers are incorporated in a rather stiff supramolecular assembly like peptide fibers. The paper also shows that mixtures of simple L-valine-based oligopeptides provide a flexible mineralization platform for the tuning of hybrid nanostructures. As a result, our findings open the way towards a better control of metal-organic hybrid materials via the variable incorporation of functional (peptide 2) and (almost) purely structural (peptide 1) building blocks into a supramolecular scaffold. Formation kinetics and related questions are currently under investigation.

\section{Acknowledgements}

We thank Prof. E. C. Constable for access to his IR spectrometer, M. Düggelin, D. Mathys, and G. Morson for SEM measurements, Prof. L. Diamond for access to his Raman microscope, and Prof. J. Wirz for access to the Agilent spectrophotometer. The Swiss National Science Foundation, the University of Potsdam, the Max-Planck-Institute of Colloids and Interfaces, and the NCCR Nanosciences are acknowledged for financial support. A.T. thanks the Holcim Stiftung Wissen for a Habilitation Fellowship.

\section{References}

1 M. Faraday, Philos. Trans. R. Soc. London, 1857, 147, 145.

2 U. Kreibig, Z. Phys. D, 1986, 3, 239.

3 A. Henglein, Chem. Rev., 1989, 89, 1861.

4 M. Brust, J. Fink, D. Bethell, D. J. Shiffrin and C. Kiely, J. Chem. Soc., Chem. Commun., 1995, 1655.

5 M. Brust, M. Walker, D. Bethell, D. J. Shiffrin and R. Whyman, J. Chem. Soc., Chem. Commun., 1994, 801.

6 G. Schmid, Nanoparticles. From Theory to Application, Wiley-VCH, Weinheim, 2003.

7 M. C. Daniel and D. Astruc, Chem. Rev., 2004, 104, 293.

8 C. Zhan, J. Wang, J. Juan, H. Gong and M. Liu, Langmuir, 2003, 19.

9 C. S. Love, V. Chechik, D. K. Smith, K. Wilson, I. Ashworth and C. Brennan, Chem. Commun., 2005, 1971.

10 P. Gao, C. Zhan and M. Liu, Langmuir, 2006, 22.

11 S. Si and T. K. Mandal, Chem.-Eur. J., 2007, 13, 3160.

12 S. Bhattacharya, A. K. Das, A. Banerjee and D. Chakravorty, J. Phys. Chem. B, 2006, 110, 10757.

13 S. Ray, A. K. Das and A. Banerjee, Chem. Commun., 2006, 2816.

14 Y.-F. Djalali and H. M. Chen, J. Am. Chem. Soc., 2003, 125, 5873.

15 J. M. Slocik and D. M. Wright, Biomacromolecules, 2003, 4, 1135.

16 X. Mo, M. P. Krebs and S. M. Yu, Small, 2006, 2, 526.

17 Q. Dong, H. Su and D. Zhang, J. Phys. Chem. B, 2005, 109, 17429.

18 A. Mantion and A. Taubert, Macromol. Biosci., 2007, 7, 208.

19 M. Sunde, L. C. Serpell, M. Bartlam, P. E. Fraser, M. B. Pepys and C. C. F. Blake, J. Mol. Biol., 1997, 273, 729.

20 J. A. Jarvis, D. J. Craik and M. C. J. Wilce, Biochem. Biophys. Res. Commun., 1993, 192, 991.

21 A. Manna, B. D. Kulkarni, K. Bandyopadhyay and K. Vijayamohanan, Chem. Mater., 1997, 9, 3032.

22 J. J. Mock, M. Barbic, D. R. Smith, D. A. Schultz and S. Schultz, J. Chem. Phys., 2002, 116, 6755 .

23 I. O. Sosa, C. Noguez and R. G. Barrera, J. Phys. Chem. B, 2003, 107, 6269.

24 K. L. Kelly, E. Coronado, L. L. Zhao and G. C. Schatz, J. Phys. Chem. B, 2003, 107, 668.

25 T. C. Deivaraj, N. L. Lala and J. Y. Lee, J. Colloid Interface Sci., 2005, 289, 402.

26 S. Y. Kang and K. Kim, Langmuir, 1998, 14, 226.

27 A. Kumar, H. Joshi, R. Pasricha, A. B. Mandale and M. Sastry, J. Colloid Interface Sci., 2003, 164, 396.

28 C. D. Wagner, W. M. Riggs, C. E. Davis, J. F. Moulder, in Handbook of X-Ray Photoelectron Spectroscopy, ed. G. E. Muilenberg, PerkinElmer Corporation, Eden Praire, 1979, p. 122.

29 J. C. Munro and C. W. Frank, Polymer, 2003, 44, 6335.

30 C. J. Sandroff and D. R. Herschbach, J. Phys. Chem., 1982, 86, 3277. 
31 C.-J. Zhong and M. D. Porter, J. Am. Chem. Soc., 1994, 116, 11616.

32 H. Lee, M. S. Kim and S. W. Suh, J. Raman Spectrosc., 1991, 22, 91

33 G. Xue, M. Ma, J. Zhang, Y. Lu and K. T. Carron, J. Colloid Interface Sci., 1992, 150, 1.

34 E. Podstawka, Y. Ozaki and L. Proniewicz, Appl. Spectrosc., 2004, 58, 570 .

35 E. Podstawka, Y. Ozaki and L. Proniewicz, Appl. Spectrosc., 2004, 58, 581 .

36 B. A. Sexton and R. J. Madix, Chem. Phys. Lett., 1980, 76, 294

37 B. Pettinger and H. Wetzel, Chem. Phys. Lett., 1981, 78, 398.

38 G. K. Fukin, S. V. Lindeman and J. K. Kochi, J. Am. Chem. Soc., $2002, \mathbf{1 2 4}, 8329$.

39 S. V. Lindeman, R. Rathore and J. K. Kochi, Inorg. Chem., 2000, 39 , 5707.

40 J.-R. Lo, X.-H. Bu, J. Jiao, W.-P. Du, X.-H. Xu and R.-H. Zhang, Dalton Trans., 2005, 464

41 J. Seo, M. R. Song, J.-E. Lee, S. Y. Lee, I. Yoon, K.-M. Park, J. Kim, J. H. Jung, S. B. Park and S. S. Lee, Inorg. Chem., 2006, 45, 952.
42 P. R. Selvakannan, S. Mandal, S. Phadtare, A. Gole, R. Pasricha, S. D. Andyanthaya and M. Sastry, J. Colloid Interface Sci., 2004, 269, 97.

43 R. R. Naik, S. J. Stringer, G. Agarwal, S. E. Jones and M. O. Stone, Nat. Mater., 2002, 1, 169.

44 Z. L. Wang, J. Phys. Chem. B, 2000, 104, 1153.

45 S. Si, R. R. Battacharjee, A. Banerjee and T. K. Mandal, Chem.-Eur. J., 2006, 12, 1256.

46 B. Simmons, S. Li, V. T. John, G. L. McPherson, C. Taylor, D. K. Schwartz and K. Maskos, Nano Lett., 2002, 2, 1037.

47 B. Wiley, Y. Sun and Y. Xia, Acc. Chem. Res., 2007, 40, 1067.

48 A. V. Akimov, A. Mukherjee, C. L. Yu, D. E. Chang, A. S. Zibrov, P. R. Hemmer, H. Park and M. D. Lukin, Nature, 2007, 450, 402.

49 R. Gunawidjaja, C. Jiang, S. Peleshanko, M. Ornatska, S. Singamaneni and V. V. Tsukruk, Adv. Funct. Mater., 2006, 16, 2024.

50 X. Sun and Y. Li, Adv. Mater., 2005, 17, 2626.

51 G. Xue and J. Dong, Anal. Chem., 1991, 63, 2393. 